\title{
Central Venous Cannula Insertion
}

National Cancer Institute

\section{Source}

National Cancer Institute. Central Venous Cannula Insertion. NCI Thesaurus. Code C40972.

A procedure of surgical placement of a catheter, which lumen is usually occupied by a trocar, into the central vein (internal jugular, subclavian, and femoral often used) or veins, to provide vascular access for measurement of hemodynamic variables that cannot be measured accurately by noninvasive means. It also can be used to deliver medications that were too potent or too toxic to be administered through peripheral access, for parenteral nutrition delivery; and for placing wires and pulmonary artery catheters. Central veins are usually cannulated percutaneously. The procedure is associated with many adverse events and has to be performed or supervised by an experienced physician. 